\title{
A Discussion of Social Science Research as Systematic Inquiry
}

\author{
Shaun J. Manning, PhD* \\ South Korea \\ *Corresponding Authors: Shaun J. Manning, PhD, South Korea

\begin{abstract}
In the social sciences, research has three key considerations: systematicity, data that lead to facts, and a useful conclusion. Many newcomers to English Language Teaching, English Education, and other social science research need to understand the differences between anecdotal and scientific evidence. The latter has requirements related to design, data, and conclusions that allow for meaningful conclusions to be drawn about the relationships among the elements in the researched setting. This paper presents an easy-toread introduction to the nature of social sciences research for the newcomer to doing and consuming research.
\end{abstract}

Keywords: Social science research, information, philosophy of science, research design

\section{INTRODUCTION}

We appear to do research all the time. We compare prices before purchasing, we try on clothes in a store before we buy, we date before we marry, and we read restaurant reviews before going out to eat. However, these activities, which potentially could be considered research, fall short of the type of research educators, academics, scientists, and marketers do. These people work from a narrower sense of the term and consider research, "setting out to discover something directly about the world" [1]. The Oxford American College Dictionary concurs. It defines research as, "the systematic investigation into and study of materials and sources in order to establish facts and reach new conclusions" [2]. True research, therefore, has three key components: (1) systematic investigation, with a purpose, a clear design, and following a logical procedure; (2) an attempt to determine facts through valid analysis; and (3) a conclusion or claim which is relevant and worthy of reading (Richards, 2003, pp. 3-5).

\section{The COMPONENTS OF Social SCIENCE RESEARCH}

Research is systematic investigation, not the anecdotal noticing of salient events. This means any research project has a purpose, design, and logical procedure. To illustrate this, consider the following example. One Monday morning, we may anecdotally notice that our favourite coffee shop has no other customers and conclude, "It's Monday, so everyone is too busy to enjoy a cup of coffee." However, there could be many other reasons for the absence of customers that morning, and the real reason(s) has nothing to do with the day of the week. To determine the reason for a lack of customers, we would have to determine the number of customers on different days of the week, and at different times of the year (by observing), or ask customers their preferences (by an interview, survey, or both). We could also try closing the coffee shop on Monday morning and seeing if any customers complained. Any of these approaches would come closer to meeting the requirement of systematic investigation.

The purpose of the research is to answer a question. In our coffee shop example: "(Why?) Do customers avoid the coffee shop on Mondays?" Armed with the purpose, we need to design our study. There are many textbooks written about the design of research, but generally there are two approaches: a qualitative approach, observing the situation as it naturally exists and perhaps interviewing some of the people involved; and a quantitative approach, changing the situation in one and only one important characteristic and measuring the changes [See, for example: ,3-6]. The researcher must decide how much and what type of data will be needed to answer the question. However, researchers have lives away from their research - they cannot sit in the coffee shop 24 hours a day, 7 days a week, 365 days a year. Even if they could, would this much observation be necessary (probably not) and 
what would the researchers look for? They could observe, for example: the number of different people, the number of visits (i.e. one customer may visit the same shop six times a week), the average time people spend sitting in the shop, or something else?

In the design phase, researchers may consider replacing direct data (observation) with indirect data. For example, they might wish to use sales receipts to determine the number of customers. This is a possibility, but sometimes two people share one coffee, or one person buys more than one cup for themselves, so sales receipts will not tell us how many people are in the shop. A more direct approach would be to put a security camera at the front of the coffee shop and record the people coming entering and exiting. Later we could review the video and get an accurate count of the visitors to the shop. Unfortunately, not all people who enter are customers; some may visit just to use the toilet. This also introduces inaccuracy into our data. It is the researcher's task, before starting out on a project, to arrange the design so that the data is gathered in a systematic manner that allows for logical conclusions while minimizing inaccuracy.

A logical procedure uses data collection tools that, when applied with an appropriate design, give us valid information. For example, we could ask the staff to record the customers and the time by making a tick on a piece of paper (i.e. use a 'tally sheet') every time a customer both entered and made a purchase- thereby excluding those who enter without purchasing and those who may enter, stay a long time and make two or more purchases. Meanwhile, we could give customers a survey that asked about what day and time they usually visited the shop, and finally we could interview a few customers. This would give us the number of customers per day and time, a limited view of what many customers think, and a detailed view of what a few customers think about coming to the shop on Mondays.

\section{THE RESULTS OF RESEARCH: NEW FACTS}

Research sheds light on the state of the world by establishing facts. Facts however, are not without problems. Some facts are universally true, e.g. distilled liquid water freezes at $0^{\circ} \mathrm{C}$ at sea-level; whereas others are situated, e.g. 57\% of people drink at least 2 cups of coffee per day ${ }^{1}$. In the latter example we need to know what city the people are in, the availability of coffee, the price of coffee, etc. because these and many other situational factors influence the purchase of coffee. Research, ultimately, looks for universal facts, but most often reports situated ones. This means that an investigation of one coffee shop may establish facts that are useful for all coffee shops (e.g. you need ground, roasted coffee beans and hot water) along with facts that are pertinent only to the particular coffee shop that was investigated (e.g. the customers' preferred background music). Readers of research need to critically examine the facts found by the researcher to determine if they apply only to the researched situation, or if they apply to the reader's situation as well.

Moreover, how the facts are garnered from the data requires care. Sometimes numbers do not represent reality. For example, if a Korean company needs someone to sell its products overseas, this is often done in English [7]. The company may hire someone with a high TOEIC score because TOEIC scores represent a general English ability [8]. The CEO may then be shocked when their new staff member cannot give a business presentation. He should not be, because the TOEIC has not measured presentation skill. He used the wrong measure of presentation ability. Likewise, when carrying out research, researchers need to make sure the numbers validly represent reality; otherwise they have a false 'fact'. Consider the fuel gauge in a car. Drivers think it measures how much gasoline is in the tank, but if they fill their tank with water, the gauge reads 'FULL' but their car will not go anywhere. The fuel gauge does not measure gasoline, but rather, it measures the amount of any liquid that happens to be in the tank. It is an indirect measure that relies on an underlying assumption- that people will only put gasoline in their tank, i.e. the contents of the tank are known, and therefore 'FULL' means there is gasoline in the car. A direct measure of gasoline would then have to include an independent chemical analysis of the contents of the tank along with fuel gauge reading.

This idea is important in the social sciences because there often is no way to independently verify the construct social scientists are measuring. Constructs like 'intelligence', 'motivation', 'satisfaction', etc. are impossible to ascertain directly. Any measure of these must be carefully validated, by triangulating their results with other measures, observations, interviews, etc. to give a more robust

\footnotetext{
${ }^{1}$ This is an invented number - I have no idea how many cups of coffee people drink!
} 
picture of the construct. For example can never know the amount of 'intelligence' in the brain the same way we know the amount of fuel in the gas tank, for although we have indirect measures of both: an IQ test and a fuel gauge, we only have direct measures of the latter: a chemical test that validates the content of the tank is gasoline. There is no direct measure of intelligence. We must look at multiple indirect measures of intelligence and hope they are close to reality.

Data can be numeric: test scores, Likert scale rankings, housing prices, and the like. Data can also be non-numeric, what I call 'WAPs' (words, artefacts, and paralanguage), for example: the responses spoken in to interview questions, the color and style of someone's clothes, the distance two people stand apart from each other, etc. However, data are not facts. Data are simply individual items of information sought, created, or observed by the researcher. Only when the data collection design tools and their implementation are appropriate, the data produced by the tools can be considered facts. If the collection tool or the design for collecting it are not appropriate, we have useless data.

\section{The Design OF A STUdY}

In the systematic gathering of data, we must think in terms of three interrelated levels: approach or design, data, and analysis[9]. There are two 'pure' designs, commonly called 'Quantitative' and 'Qualitative' research respectively. Figure 1 compares these two pure forms. Quantitative research involves the researcher manipulating a situation or event in such a way that a key aspect differs between two or more groups of people and then measuring any changes (in behavior, outcome, etc.) caused by the manipulation. Qualitative research, on the other hand does not manipulate or change events, it just observes and records.

\begin{tabular}{|c|c|c|}
\hline & Normative: "Quantitative", Positivistic & Interpretative: "Qualitative", Holistic \\
\hline $\begin{array}{l}\text { Theoretical } \\
\text { orientation }\end{array}$ & $\begin{array}{l}\text { Social phenomena are rule-governed; methods } \\
\text { from sciences can be applied; looking at } \\
\text { averages }\end{array}$ & $\begin{array}{l}\text { Social phenomena are contextualized; its } \\
\text { investigation is subjective and relative; } \\
\text { methods from anthropology/ social psych }\end{array}$ \\
\hline $\begin{array}{l}\text { Aiming to } \\
\text { find }\end{array}$ & Universal truths on a highly specific question & Situated explanation leading to theory \\
\hline \multirow[t]{3}{*}{ How } & & \multirow{3}{*}{$\begin{array}{l}\text { Describe and understand why (A) happens in } \\
\text { this situation } \\
\text { Using thick, holistic description, triangulation } \\
\text { of data, and multiple perspectives to arrive at } \\
\text { an explanation }\end{array}$} \\
\hline & Falsify existing theory & \\
\hline & $\begin{array}{l}\text { Determine the effect of changing an } \\
\text { independent variable on a measurable, } \\
\text { dependent variable }\end{array}$ & \\
\hline $\begin{array}{l}\text { Approach / } \\
\text { Design }\end{array}$ & Experimental manipulation & Observation without manipulation \\
\hline Data type & Numeric & Words, artefacts, paralinguistic cues (WAPs) \\
\hline \multirow{2}{*}{$\begin{array}{l}\text { Analysis and } \\
\text { interpretation }\end{array}$} & \multirow[t]{2}{*}{ Statistical (Descriptive and inferential) } & Philosophical, humanistic, interpretative \\
\hline & & $\begin{array}{l}\text { Identification and explanation of major } \\
\text { themes }\end{array}$ \\
\hline
\end{tabular}

Figure1. Comparison of Quantitative and Qualitative Research

There are potential variants of these two 'pure' forms of research, commonly referred to as mixed methods. Figure 2 shows the possible approach-data-analysis combinations. (Columns A and $\mathrm{H}$ represent the quantitative and qualitative forms given in Figure 1.) 


\begin{tabular}{|llllllllll|}
\hline & A & B & C & D & E & F & G & H \\
\hline Design/ & Manipulate & Manipulate & Manipulate & Manipulate & Observe & Observe & Observe & Observe \\
Approach & & & & & & & & \\
\hline Data & Numeric & Numeric & WAPs & WAPs & Numeric & Numeric & WAPs & WAPs \\
\hline Analysis & Statistical & Thematic & Statistical & Thematic & Statistical & Thematic & Statistical & Thematic \\
\hline
\end{tabular}

Figure2. The potential research designs (based on [9])

Figure 2 shows that when manipulating situations, we can still obtain non-numeric data. For example: we can artificially create a longer waiting time in a restaurant and then interview people ask people what they feel about the service, then compare their answers to those of people who went to the restaurant when we did not increase the waiting time. Likewise, without numeric data (e.g. words) we can still perform statistical analyses. What is needed is an operational definition - a consistent and agree-upon procedure - to convert non-numeric data to numbers. For example: ESL learners' essays can be rated by professors according to a standardized rubric - and a number assigned, or the number of words in the essay can be counted and compared to the number of grammatical errors made, etc. Finally, observational studies can also produce numeric data - we can count how many times a teacher asks female students questions and compare to how many times the teacher asks male students. The teacher has not been told to ask more questions to one gender than the other (that would be an experimental manipulation), we just watch and see what the teacher does (observation). The frequency count is numeric data.

Most important to the analysis of research is that research is useful - its conclusions and claims should be relevant to society, even in a small way. This does not mean it must be worthy of a Nobel Prize, merely that it should help someone else. For example, determining the average height of a coffee shop's tables will be useful to a table-maker; knowing the average size of an airline's seats is important to larger passengers; and, if the coffee shop owner determines there are no customers on Mondays, they can take the day off. Even though the usefulness of some research may not be known until after it is published, researchers should envision an intended end-user, or audience, for their findings during the planning of the project. Failure to do so could lead to a considerable amount of wasted time and effort.

\section{CONCLUSION}

In conclusion, when doing research, as opposed to reporting anecdotes or opining, the researcher must create research with a systematic approach having a clear, logical purpose, design, and procedure; valid analysis methods that determine facts; and conclusions useful for society. In this era of fake news and pseudoscience, the reader must also actively critique any research along these same dimensions. By holding research to a high standard, everyone gains.

\section{REFERENCES}

[1] K. Richards, Qualitative Inquiry in TESOL (Palgrave Macmillan, New York, 2003).

[2] Oxford University Press, Oxf. Am. Coll. Dict. 1153 (2006).

[3] R. Ellis and G. P. Barkhuizen, Analysing Learner Language (Oxford University Press, Oxford; New York, 2005).

[4] C. Grbich, Qualitative Data Analysis: An Introduction (Sage, London, 2006).

[5] S. Hesse-Biber, Mixed Methods Research: Merging Theory with Practice (Guilford Press, New York, 2010).

[6] L. Plonsky and S. M. Gass, Lang. Learn. 61, 325 (2011).

[7] S. J. Manning, Int. J. Foreign Stud. 9, 3 (2016).

[8] ETS, (2016). 
[9] R. Grotjahn, in Introsp. Second Lang. Res., edited by C. Faerch and G. Kasper (Multilingual Matters, Clevendon, 1987).

\section{AUTHORS' BIOGRAPHY}

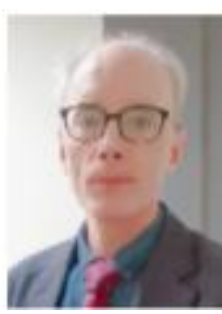

Shaun Justin Manning holds a PhD from Victoria University of Wellington. He is an associate professor in the Department of English Linguistics and Language Technology at Hankuk University of Foreign Studies, Seoul, South Korea. His research interests include research methodology, TBLT, EFL writing, AWE applications, classroom dynamics, collaborative learning, and learner identity.

Citation: Shaun J. Manning, PhD. "A Discussion of Social Science Research as Systematic Inquiry " International Journal on Studies in English Language and Literature (IJSELL), vol 8, no. 8, 2020, pp. 08-12. doi: http://dx.doi.org/10.20431/2347-3134.0808002.

Copyright: (C) 2020 Authors. This is an open-access article distributed under the terms of the Creative Commons Attribution License, which permits unrestricted use, distribution, and reproduction in any medium, provided the original author and source are credited. 